\title{
Fatty Acid Determination in Fermented Milk Samples Employing Direct Esterification and Gas Chromatography
}

\author{
Angélica F. B. Piccioli, ${ }^{a, b}$ Patrícia D. S. Santos, ${ }^{a, b}$ Roberta da Silveira, ${ }^{c, d}$ Elton Bonafé ${ }^{a, c}$ \\ Jesuí V. Visentainer ${ }^{a, b}$ and Oscar O. Santos ${ }^{\circledR} *, a, b$ \\ aPrograma de Pós-Graduação em Química, Universidade Estadual de Maringá, \\ Av. Colombo, 5790, 87020-900 Maringá-PR, Brazil \\ ${ }^{b}$ Departamento de Química, Universidade Estadual de Maringá, \\ Av. Colombo, 5790, 87020-900 Maringá-PR, Brazil \\ 'Programa de Pós-Graduação em Ciência dos Alimentos, Universidade Estadual de Maringá, \\ Av. Colombo, 5790, 87020-900 Maringá-PR, Brazil \\ ${ }^{d}$ Departamento de Ciência dos Alimentos, Universidade Estadual de Maringá, \\ Av. Colombo, 5790, 87020-900 Maringá-PR, Brazil
}

\begin{abstract}
The developed method (DM) allows to perform experiments in shorter time with reduced amount of sample and reagent for fatty acids (FA) determination in fermented milk samples. Design Expert software was employed to discover the greatest sonication time ( 7 and $20 \mathrm{~min}$ ) and concentration for alkaline and acidic reactions $\left(0.70\right.$ and $\left.1.5 \mathrm{~mol} \mathrm{~L}^{-1}\right)$. Validation procedures were applied in yogurt samples with diverse fat content, ranging from 1.22 to $2.83 \%$, being in agreement with acceptable values. Besides, the intraday relative standard deviation (RSD) (1.86\%) and interday RSD (4.23\%) values confirmed the good accuracy of the proposed method for FA derivatization.
\end{abstract}

Keywords: fermented milk, design expert, derivatization, gas chromatography

\section{Introduction}

Yogurt is a dairy derivative produced from the fermentation of milk by bacteria, such as: Lactobacillus bulgaricus and Streptococcus thermophilus. Lactose fermentation, achieved by these bacteria, produces lactic acid, which acts on milk protein contributing to the texture, composition and sensorial properties characteristic of this beverage. ${ }^{1}$ Yogurt has been defined by doctors and nutritionists as "super food", promoted by improving health, slowing aging and preventing the progression of changes in our body that lead to the development of diseases such as: diabetes, hypertension, Alzheimer and cancer. ${ }^{2}$ These human health benefits attributed to fermented milk are related to the conjugated linoleic acids (CLA); fatty acids (FA) found mainly in dairy products. ${ }^{2}$ Several studies confirm that fermented dairy products contain higher levels of CLA than unfermented milk. ${ }^{3}$

Determining the FA amount in fermented milk

\footnotetext{
*e-mail: oliveirasantos.oscardeoliveira@gmail.com
}

contributes to a better understanding of its nutritional characteristics. In addition, considering the importance of food safety and the expansion of milk and dairy production, monitoring the quality of these products is extremely important. ${ }^{4}$ Generally, yogurt samples contain about $3.25 \%$ of FA, nevertheless lower (0.5-3\%) values can also be found or even the FA absence $(<0.5 \%){ }^{5}$

Total lipids are usually extracted from milk samples with Folch ${ }^{6}$ or Bligh and Dyer ${ }^{7}$ methodologies, even though both methodologies were developed for different matrices (brain tissue and fish muscle, respectively). ${ }^{8}$ However, lipid extraction procedures are time-consuming and utilize large amount of toxic solvents (chloroform and methanol). Furthermore, extensive sample manipulation (agitation, phase separation, filtration and solvent evaporation) increases the error probability. ${ }^{9}$ Plus, after lipid extraction, it is indispensable to convert the FA into methyl esters; more volatile compounds, in order to perform the gas chromatography. It can be carried out by different methylation/esterification methodologies (depending on the sample characteristics). ${ }^{10}$ 
Direct esterification is a methodology that has been highlighted for FA determination. ${ }^{11}$ This esterification method does not require previous lipid extraction, consumes smaller amounts of solvent and sample, and also reduces steps, occasioning the reduction of errors propagated during the esterification process. ${ }^{3-12}$ The use of chemometric tools in the direct esterification procedure allows a better study of some parameters employed in this methodology, such as: amount of sample, time of esterification and concentrations of the esterifying reagents, helping to obtain optimum experimental conditions of esterification and, consequently, better results.

Some direct esterification methodologies have already been proposed for FA determination in milk and fermented milk samples, however, it has not been optimized. In addition, in some cases, $\mathrm{BF}_{3}{ }^{3}$ is used in the acid catalysis during the direct esterification process; although it is widely used, this substance in methanol is extremely toxic. ${ }^{13}$

Therefore, the aim of this work is to develop a fast, simple, direct esterification method (DM) employing smaller volumes of sample and solvent, using reagents of lower toxicity for FA determination in fermented milk samples.

\section{Experimental}

\section{Reagent and materials}

Chloroform, methanol, $n$-heptane, sulfuric acid, sodium hydroxide and potassium hydroxide were used without further purification and purchased from Millipore Sigma (Darmstadt, Germany). A mixture of fatty acid methyl esters (FAMEs, 189-19) and methyl tricosanoate, were also purchased from Millipore Sigma (St. Louis, MO, USA). Fermented milk samples from different brands were obtained in the local market (Maringá, Paraná, Brazil) and stored in refrigerator until analysis.

\section{Gas chromatographic analysis}

Chromatographic analysis was performed on a Thermo Scientific gas chromatograph (GC) equipped with flame ionization detector (FID), split/splitless injector and CP-7420 fused silica capillary column (Select FAME, $100.0 \mathrm{~m}$ long, $0.25 \mathrm{~mm}$ internal diameter and $0.25 \mu \mathrm{m}$ thin film of cyanopropyl as stationary phase). The injector and detector temperatures were $235{ }^{\circ} \mathrm{C}$. The column temperature was raised to $65^{\circ} \mathrm{C}$ for $4 \mathrm{~min}$, followed by a $16{ }^{\circ} \mathrm{C} \mathrm{min}{ }^{-1}$ heating ramp to $185{ }^{\circ} \mathrm{C}$, which was held for $12 \mathrm{~min}$. Thereafter, a new ramp of $20^{\circ} \mathrm{C} \mathrm{min}^{-1}$ was applied up to $235^{\circ} \mathrm{C}$ and maintained for $14 \mathrm{~min}$, totaling an analysis time of $40 \mathrm{~min}$. Gas flows were $1.2 \mathrm{~mL} \mathrm{~min}^{-1}$ for carrier

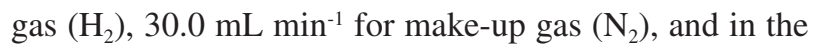
FID 30.0 and $300.0 \mathrm{~mL} \mathrm{~min}{ }^{-1}$ of gas $\left(\mathrm{H}_{2}\right)$ and synthetic air, respectively. The samples were injected in split mode, with 1:40 ratio. Injection volume was $1.0 \mu \mathrm{L}$. FAMEs were identified by comparison among the retention time of constituents samples and Sigma FAMEs. The correction factor was used and calculated to obtain FA concentrations according to Visentainer ${ }^{14}$ and FA amount was calculated in $\mathrm{mg} \mathrm{g}^{-1}$ of sample. FID correction is necessary due to the magnitude signal generated by detector in proportion to the number of $\mathrm{C}^{+}$that are bounded to hydrogen atoms.

\section{Mass spectrometry analysis}

In order to verify the esterification efficiency of the developed method in comparison to the conventional methodology of extraction followed by the methylation step, a direct infusion analysis by mass spectrometry with electrospray ionization (ESI-MS) was carried out, and consequently, the samples lipid profiles were obtained. Lipid samples $(50 \mu \mathrm{L})$ were diluted in chloroform $(950 \mu \mathrm{L})$, an aliquot of $5.0 \mathrm{~mL}$ of this solution was added into $1.0 \mathrm{~mL}$ of a methanol/chloroform mixture $(9: 1, \mathrm{v} / \mathrm{v})$ and lastly $20 \mu \mathrm{L}$ of ammonium formate $\left(0.10 \mathrm{~mol} \mathrm{~L}^{-1}\right.$ in methanol) were added.

The final solution was infused directly into a triplequadrupole Xevo-TQD mass spectrometer equipped with a Z spray ${ }^{\mathrm{TM}}$ electrospray ionization source (Waters, Milford, MA, USA). Lipid profiles were obtained ranging from $\mathrm{m} / \mathrm{z} 100$ to 1200 and extracted in positive ion (ESI+) mode. The ESI source parameters were as follows: source temperature $150{ }^{\circ} \mathrm{C}$, desolvation temperature $200{ }^{\circ} \mathrm{C}$, capillary voltage $3.0 \mathrm{kV}$, and cone voltage $20.00 \mathrm{~V}$. High purity nitrogen produced by a nitrogen generator (NM32LA, Peak Scientific ${ }^{\circledR}$, Renfrewshire, Scotland) was used as desolvation gas with a flow rate of $500 \mathrm{~L} \mathrm{~h}^{-1}$.

\section{Validation parameters}

Validation parameters were determined in accordance to International Conference on Harmonization guidelines. ${ }^{15}$ Figures of merit used were: precision, accuracy and application range, which were obtained with five replicates. The relative standard deviations (RSD) and the replication was performed in different days. Accuracy was obtained comparing results of the conventional methodology (CM) with the developed methodology (DM).

Conventional methodology for lipid extraction and esterification/transesterification (CM)

The lipid extraction was performed according to Folch ${ }^{6}$ 
methodology; approximately $10 \mathrm{~g}$ of samples were weighed in a $250.0 \mathrm{~mL}$ beaker, then $200.0 \mathrm{~mL}$ of a chloroform/ methanol mixture $(2: 1, \mathrm{v} / \mathrm{v})$ was added while stirring vigorously for $2 \mathrm{~min}$, the obtained solution was filtered on a No. 1 Whatman filter paper in Buchner funnel coupled to a vacuum pump. $30.0 \mathrm{~mL}$ of chloroform and $30.0 \mathrm{~mL}$ of distilled water were added into the filtrate and stirred again for $2 \mathrm{~min}$, and subsequently filtered. After filtration, the resulting solution was transferred to a $250 \mathrm{~mL}$ separation funnel. The extremity containing chloroform and the lipids were transferred to a pre-weighed flat bottom flask and finally the solvent was rotavaporated.

The esterification and transesterification were performed using $\mathrm{ISO}^{16}$ methodology; $100.0 \mathrm{mg}$ of sample were weighted, $2 \mathrm{~mL}$ of $n$-heptane and $2 \mathrm{~mL}$ of $\mathrm{KOH} /$ methanol solution $\left(2 \mathrm{~mol} \mathrm{~L}^{-1}\right)$ were added, the solution was stirred for $2 \mathrm{~min}$ and the organic phase was collected for further GC analysis.

\section{Experimental design}

A central composite design was generated by the Design Expert@ 7 program ${ }^{17}$ in order to evaluate the influence of sonication time and acid and alkaline concentration on the efficiency of the methylation/direct transesterification process for FA determination in fermented milk samples. The acid and alkaline time levels -1 and +1 were 7.0 and $20.0 \mathrm{~min}$, respectively, while the acid and alkaline concentration levels -1 and +1 were 0.7 and $1.5 \mathrm{~mol} \mathrm{~L}^{-1}$. The axial point $( \pm \alpha)$ for the rotational system $(\mathrm{k}<5)$ was \pm 1.4142 applied to calculate the quadratic terms in Table 1. Five repetitions were performed at the central point, totaling 29 experiments.

\section{Developed methodology for the lipid methylation procedure (DM)}

$250 \mu \mathrm{L}$ of fermented milk was added into $10 \mathrm{~cm}$ test tubes and $2 \mathrm{~mL}$ of $\mathrm{NaOH} /$ methanol were added. The tubes were placed in an Eco-Sonics Q 5.9/25 ultrasound bath (Unique, São Paulo, Brazil) with $165 \mathrm{~W}$ of power and $25 \mathrm{kHz}$, being evaluated alkaline concentrations and reaction times, according to the experimental design. After the alkaline reaction, $2 \mathrm{~mL}$ of $\mathrm{H}_{2} \mathrm{SO}_{4} /$ methanol were added, being its concentration and reaction time evaluated according to the experimental design. $1.0 \mathrm{~mL}$ of $n$-heptane and $500 \mu \mathrm{L}$ of internal standard (PI, 23:0 m) were added, the tubes were shaken for $30 \mathrm{~s}$, then centrifuged at $2000 \mathrm{rpm}$ for $1.0 \mathrm{~min}$. Subsequently, the upper phase was collected for injection in the GC.

\section{Results and Discussion}

\section{Experimental design and model optimization}

Table 2 displays the FA sums results for fermented milk samples in different experimental trials for the central composite experimental design. The experiment 11 obtained the highest result $\left(7.37 \mathrm{mg} \mathrm{g}^{-1}\right)$. In order to evaluate the obtained model and the interaction among the factors, the results were studied by analysis of variance (ANOVA) and the response surface generated by the Design Expert $^{\circledR} 7$ program. ${ }^{17}$ Therefore, cubic was selected due to its high order of significance, low absence of adjustment, and reasonable agreement between the correlation coefficient obtained and the predicted correlation coefficient for the model. The results obtained by ANOVA are exposed in Table 1.

The $F$ value of 7.35 demonstrate that the model is significant. There is merely $1.00 \%$ of chance that the $F$ value occur due to noise. Probability values inferior than 0.0500 indicate that the model terms are significant. Thus A, B, ACD are significant. Values superior than 0.100 indicate that the model terms are not significant. The $F$ value (2.54) for absence of adjustment indicates that it is not significant in relation to the pure error. There is $19.41 \%$ of chance that the $F$ value absence of adjustment may be higher due to noise.

Table 1. ANOVA parameter models for develop methodology (DM) in fermented milk

\begin{tabular}{lcccccc}
\hline & Square sum & LD $^{\mathrm{a}}$ & Square & $F$ value & \multicolumn{2}{c}{${\text { Prob }>F^{\mathrm{b}}}^{\mathrm{c}}$} \\
\hline Model & 82.36 & 22 & 3.74 & 7.35 & 0.0100 & $\mathrm{~S}^{\mathrm{f}}$ \\
$\mathrm{A}^{\mathrm{c}}$ & 12.29 & 1 & 12.29 & 24.13 & 0.0027 & - \\
$\mathrm{B}^{\mathrm{d}}$ & 12.62 & 1 & 12.62 & 24.77 & 0.0025 & - \\
$\mathrm{ACD}^{\mathrm{e}}$ & 3.53 & 1 & 3.53 & 6.93 & 0.0390 & - \\
Residue & 3.06 & 6 & 0.51 & - & - & - \\
Absence of adjustment & 1.71 & 2 & 0.85 & - & -1941 & - \\
Pure error & 1.35 & 4 & 0.34 & - & - & - \\
Total core & 85.42 & 28 & - & - & - \\
\hline
\end{tabular}

${ }^{\mathrm{a}} \mathrm{LD}$ : freedon degree; ${ }^{\mathrm{b}} \mathrm{Prob}>\mathrm{F}$ : probability value associated with $F$ value; ${ }^{\mathrm{c}} \mathrm{A}: \mathrm{NaOH}$ concentration; ${ }^{\mathrm{d}} \mathrm{B}: \mathrm{H}_{2} \mathrm{SO}_{4}$ concentration; ${ }^{\mathrm{e}} \mathrm{ACD}$ : interaction between $\mathrm{NaOH}$ concentration (A), $\mathrm{NaOH}$ retention time (C) and $\mathrm{H}_{2} \mathrm{SO}_{4}$ retention time (D); ${ }^{\mathrm{f}} \mathrm{S}$ : significant; ${ }^{\mathrm{g}} \mathrm{NS}$ : non-significant. 
Table 2. Factors, levels and FA sum for each procedure of the experimental design

\begin{tabular}{|c|c|c|c|c|c|c|c|c|c|c|}
\hline & \multirow{2}{*}{ Experiment } & \multicolumn{2}{|c|}{$\begin{array}{c}\text { Concentration of } \mathrm{NaOH} \\
\text { in methanol }\end{array}$} & \multicolumn{2}{|c|}{$\begin{array}{c}\text { Concentration of } \mathrm{H}_{2} \mathrm{SO}_{4} \\
\text { in methanol }\end{array}$} & \multicolumn{2}{|c|}{$\begin{array}{c}\text { Sonication time of } \mathrm{NaOH} \\
\text { in methanol }\end{array}$} & \multicolumn{2}{|c|}{$\begin{array}{c}\text { Sonication time of } \mathrm{H}_{2} \mathrm{SO}_{4} \\
\text { in methanol }\end{array}$} & \multirow{2}{*}{$\begin{array}{c}\text { FA sum / } \\
\left(\mathrm{mg} \mathrm{g}^{-1} \text { of }\right. \\
\text { sample) }\end{array}$} \\
\hline & & $\begin{array}{c}\text { Real / } \\
\left(\mathrm{mol} \mathrm{L}^{-1}\right)\end{array}$ & Coded & $\begin{array}{c}\text { Real / } \\
\left(\mathrm{mol} \mathrm{L}^{-1}\right)\end{array}$ & Coded & Real / min & Coded & Real / min & Coded & \\
\hline \multirow{16}{*}{$\begin{array}{l}\text { Full factorial } \\
\text { design }\end{array}$} & 1 & 0.70 & - & 0.70 & - & 7.00 & - & 7.00 & - & 3.03 \\
\hline & 2 & 1.50 & + & 0.70 & - & 7.00 & - & 7.00 & - & 2.38 \\
\hline & 3 & 0.70 & - & 1.50 & + & 7.00 & - & 7.00 & - & 6.68 \\
\hline & 4 & 1.50 & + & 1.50 & + & 7.00 & - & 7.00 & - & 5.89 \\
\hline & 5 & 0.70 & - & 0.70 & - & 20.00 & + & 7.00 & - & 5.00 \\
\hline & 6 & 1.50 & + & 0.70 & - & 20.00 & + & 7.00 & - & 2.13 \\
\hline & 7 & 0.70 & - & 1.50 & + & 20.00 & + & 7.00 & - & 7.04 \\
\hline & 8 & 1.50 & + & 1.50 & + & 20.00 & + & 7.00 & - & 2.86 \\
\hline & 9 & 0.70 & - & 0.70 & - & 7.00 & - & 20.00 & + & 4.51 \\
\hline & 10 & 1.50 & + & 0.70 & - & 7.00 & - & 20.00 & + & 2.03 \\
\hline & 11 & 0.70 & - & 1.50 & + & 7.00 & - & 20.00 & + & 7.37 \\
\hline & 12 & 1.50 & + & 1.50 & + & 7.00 & - & 20.00 & + & 4.94 \\
\hline & 13 & 0.70 & - & 0.70 & - & 20.00 & + & 20.00 & + & 4.57 \\
\hline & 14 & 1.50 & + & 0.70 & - & 20.00 & + & 20.00 & + & 1.94 \\
\hline & 15 & 0.70 & - & 1.50 & + & 20.00 & + & 20.00 & + & 5.52 \\
\hline & 16 & 1.50 & + & 1.50 & + & 20.00 & + & 20.00 & + & 5.14 \\
\hline \multirow{8}{*}{ Axial point } & 17 & 0.30 & $-\alpha$ & 1.10 & 0 & 13.50 & 0 & 13.50 & 0 & 6.95 \\
\hline & 18 & 1.90 & $+\alpha$ & 1.10 & 0 & 13.50 & 0 & 13.50 & 0 & 1.98 \\
\hline & 19 & 1.10 & 0 & 0.30 & $-\alpha$ & 13.50 & 0 & 13.50 & 0 & 1.94 \\
\hline & 20 & 1.10 & 0 & 1.90 & $+\alpha$ & 13.50 & 0 & 13.50 & 0 & 6.96 \\
\hline & 21 & 1.10 & 0 & 1.10 & 0 & 0.50 & $-\alpha$ & 13.50 & 0 & 3.00 \\
\hline & 22 & 1.10 & 0 & 1.10 & 0 & 26.50 & $+\alpha$ & 13.50 & 0 & 3.81 \\
\hline & 23 & 1.10 & 0 & 1.10 & 0 & 13.50 & 0 & 0.50 & $-\alpha$ & 2.50 \\
\hline & 24 & 1.10 & 0 & 1.10 & 0 & 13.50 & 0 & 26.50 & $+\alpha$ & 4.82 \\
\hline \multirow{5}{*}{ Central point } & 25 & 1.10 & 0 & 1.10 & 0 & 13.50 & 0 & 13.50 & 0 & 2.60 \\
\hline & 26 & 1.10 & 0 & 1.10 & 0 & 13.50 & 0 & 13.50 & 0 & 3.39 \\
\hline & 27 & 1.10 & 0 & 1.10 & 0 & 13.50 & 0 & 13.50 & 0 & 3.39 \\
\hline & 28 & 1.10 & 0 & 1.10 & 0 & 13.50 & 0 & 13.50 & 0 & 4.05 \\
\hline & 29 & 1.10 & 0 & 1.10 & 0 & 13.50 & 0 & 13.50 & 0 & 3.96 \\
\hline
\end{tabular}

FA: fatty acid; \pm : factor points; $\pm \alpha$ : axial points; 0 : central points.

The coefficients values of correlation $\left(\mathrm{R}^{2}, 0.9642\right)$ and variation $(17.17 \%)$ indicate that the model is acceptable. The equation obtained for the cubic model is presented in equation 1:

FA Sum $=+3.48-1.24(\mathrm{~A})+1.26(\mathrm{~B})+0.47(\mathrm{ACD})$

Observing Figure 1, which displays the influence of the interaction between the levels of alkaline and acid concentration on the responses obtained in FA sum, it is possible to verify that through the response surface towards higher acid concentration and lower alkaline concentration, higher FA sum are obtained. It means that the esterification

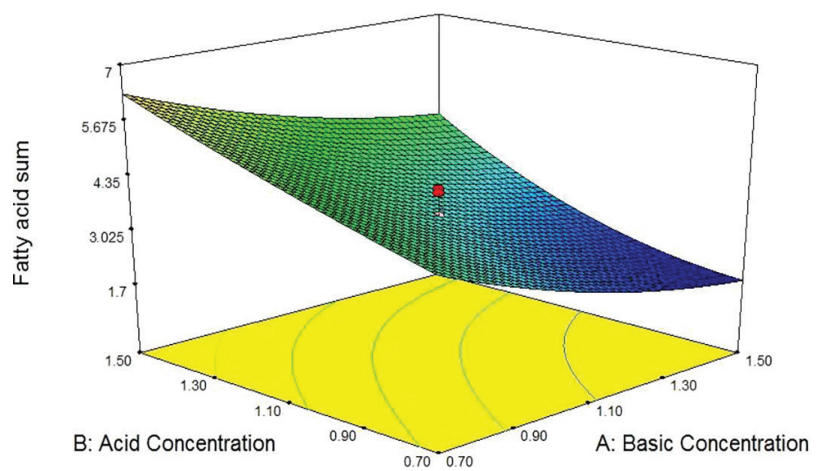

Figure 1. 3D graph of the response surface obtained for the interactions between the variables A (alkaline concentration) and B (acid concentration) in the responses as sum of FA concentration. 
is more efficient in higher acid concentration and lower alkaline concentration. Higher acid concentrations assist in the proteins precipitation, consequently, FA linked to the milk proteins may become available for the esterification reaction to occur, in this way, higher acid concentrations are preferable. Higher alkaline concentrations lead to FA saponification, decreasing the FA amount available for esterification, thus lower alkaline concentrations are preferable.

In this way, the parameters values for the DM of esterification (experiment 11) were: alkaline concentration: $0.70 \mathrm{~mol} \mathrm{~L}^{-1}$, acid concentration: $1.50 \mathrm{~mol} \mathrm{~L}^{-1}$, alkaline sonication time: $7.0 \mathrm{~min}$, acid sonication time: $20.0 \mathrm{~min}$, resulting in higher value in the FA sum in comparison to the other 28 experiments.
Mass spectrometry analysis using electrospray ionization (ESI-MS)

ESI-MS analysis is a technique that allows the confirmation and identification of components present in complex samples and also present high sensitivity and selectivity. ${ }^{18}$ Hence, the lipid profile of CM and DM (conventional method and developed method, respectively) were compared in order to verify if DM presented better results in comparison to $\mathrm{CM}$. So, the mass range analyzed in both spectra was $m / z 100-1200$. The spectrum of Figures $2 \mathrm{a}$ and $2 \mathrm{~b}$ demonstrate the mass spectra of compounds not esterified by CM and DM, respectively.

Analyzing the spectra is possible to observe that the diacylglycerols (DAG) amount detected as non-esterified
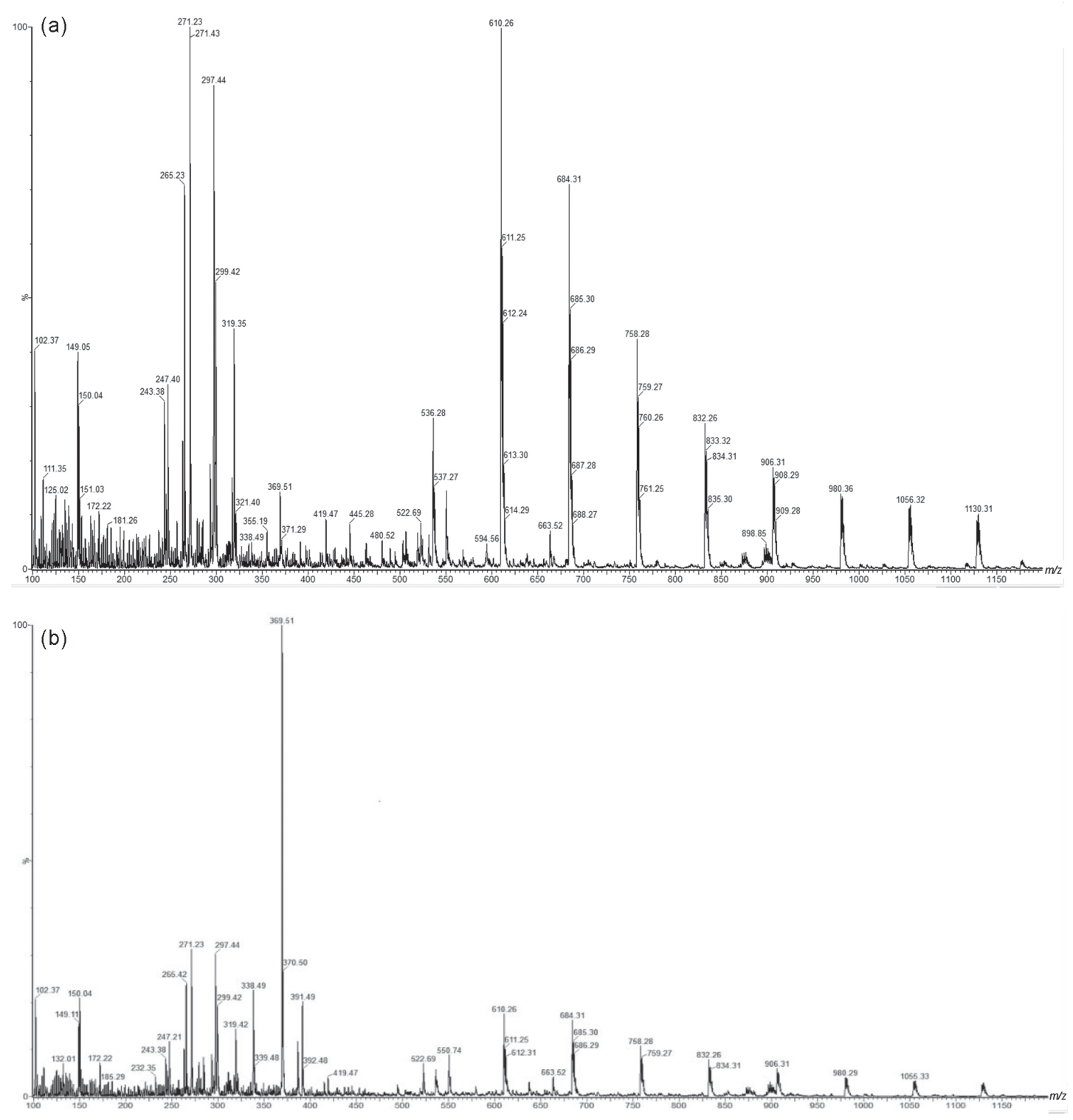

Figure 2. Lipid profile by ESI(+)-MS of the (a) derivatization of the conventional method and (b) derivatization developed in this work, focused on mass ranges of $m / z, 100-1200$. 
was lower in DM, in the same way as the residual triacylglycerols (TAG) amount.

Thus, the analysis by ESI-MS confirms the result obtained by CG-FID, since the FA sum in Table 3 for CM was $3.48 \pm 1.52 \mathrm{mg} \mathrm{g}^{-1}$ of sample, while the FA sum for DM was $6.47 \pm 0.27 \mathrm{mg} \mathrm{g}^{-1}$ of sample.

Consequently, DM is an efficient method to obtain FA in this sample due to the superior FA sum demonstrated, besides DM exposes other benefits such as the requirement of sample extraction, the reduction of reagent and time, and others benefits already mentioned.

\section{Application of the developed methodology}

The results of the FA quantification for fermented milk samples by the conventional method and by the developed method are presented in Table 3. It is possible to observe that the proposed method obtained FA sum 50\% higher in comparison to the conventional extraction and methylation/ transesterification method, demonstrating its efficiency. It is also possible to observe that the most significant

Table 3. Fatty acids quantification by conventional extraction, esterification and transesterification methodology $(\mathrm{CM})$ in comparison to developed methodology $(\mathrm{DM})(\mathrm{n}=3$, mean \pm standard error $)$

\begin{tabular}{lcc}
\hline \multirow{2}{*}{ Carbon number } & \multicolumn{2}{c}{$\mathrm{FA}^{\mathrm{a}} /\left(\mathrm{mg} \mathrm{g}^{-1}\right.$ of sample $)$} \\
\cline { 2 - 3 } & \multicolumn{1}{c}{$\mathrm{CM}^{\mathrm{b}}$} & $\mathrm{DM}^{\mathrm{c}}$ \\
\hline $14: 0$ & $0.48 \pm 0.36$ & $0.90 \pm 0.14$ \\
$16: 0$ & $1.22 \pm 2.70$ & $2.33 \pm 0.08$ \\
$18: 0$ & $0.49 \pm 2.08$ & $1.03 \pm 0.15$ \\
$18: 1 \mathrm{n}-9$ & $1.13 \pm 2.09$ & $1.79 \pm 0.19$ \\
$18: 2 \mathrm{n}-6 \mathrm{c}$ & $0.16 \pm 2.41$ & $0.42 \pm 0.07$ \\
$\sum$ FA $^{\mathrm{d}}$ & $3.48 \pm 1.52$ & $6.47 \pm 0.27$ \\
\hline
\end{tabular}

${ }^{\mathrm{a}} \mathrm{FA}$ : fatty acid; ${ }^{\mathrm{b}} \mathrm{CM}$ : conventional methodology; ${ }^{\mathrm{C}} \mathrm{DM}$ : developed methodology; ${ }^{\mathrm{d}} \Sigma \mathrm{FA}$ : sum of fatty acid. difference between the FA encountered is in the $18: 2 \mathrm{n}-2$ that ranged from $0.16 \pm 2.41 \mathrm{mg} \mathrm{g}^{-1}$ of sample in the $\mathrm{CM}$ and $0.42 \pm 0.07 \mathrm{mg} \mathrm{g}^{-1}$ of sample in the DM.

The FA results for different fermented milk samples obtained through the developed methodology are presented in Table 4. FA sums ranged from $5.32 \pm 0.11$ to $10.61 \pm 0.66 \mathrm{mg} \mathrm{g}^{-1}$ sample, being in agreement with the values reported in the literature. ${ }^{5}$

\section{Method validation}

Accuracy values ranged from 95.83 to $104.17 \%$ being within the limit of acceptable values. $\operatorname{RSD}_{\text {intraday }}(1.86 \%)$ and $\mathrm{RSD}_{\text {interday }}(4.23 \%)$ demonstrate that the DM presented good accuracy for FA derivatization, and that RSD estimation values should usually be below $20 \% .^{19}$

The application range for fermented milk samples applying DM was 1.22 to $2.83 \%$ of lipids.

\section{Conclusions}

The use of chemometric tools enable to optimize and validate a new technique DM of FA direct methylation in fermented milk samples, which, besides being more efficient, is much faster, consumes smaller amount of sample and reagents, resulting in lower costs and environmental impacts in comparison to the CM. The ESI-MS analysis allowed to evaluate the developed method efficiency, once the spectrum for DM resulted in smaller residues of DAG and TAG after the esterification reaction.

\section{Acknowledgments}

The authors thank CNPQ, CAPES and Fundação Araucária for the financial support. They also thank the state of Paraná and the Universidade Estadual de Maringá

Table 4. Fatty acid composition of fermented milk by develop methodology (DM) $(n=3$, mean \pm standard error)

\begin{tabular}{lccccc}
\hline \multirow{2}{*}{ Carbon number } & \multicolumn{5}{c}{$\mathrm{FA}^{\mathrm{a}} /\left(\mathrm{mg} \mathrm{g}^{-1}\right.$ of sample $)$} \\
\cline { 2 - 6 } & Y1 & Y2 & Y3 & Y4 & Y5 \\
\hline $12: 0$ & $0.28 \pm 0.02$ & $0.29 \pm 0.06$ & $0.27 \pm 0.15$ & $0.48 \pm 0.13$ & - \\
$14: 0$ & $1.12 \pm 0.04$ & $1.07 \pm 0.09$ & $0.84 \pm 0.06$ & $1.40 \pm 0.08$ & $0.84 \pm 0.07$ \\
$16: 0$ & $3.44 \pm 0.09$ & $2.96 \pm 0.42$ & $2.30 \pm 0.28$ & $3.90 \pm 0.30$ & $2.14 \pm 0.19$ \\
$16: 1$ & $0.18 \pm 0.03$ & $0.12 \pm 0.03$ & - & $0.26 \pm 0.07$ & - \\
$18: 0$ & $1.29 \pm 0.05$ & $1.04 \pm 0.05$ & $0.84 \pm 0.06$ & $1.44 \pm 0.12$ & $0.86 \pm 0.09$ \\
$18: 1 \mathrm{n}-9$ & $2.11 \pm 0.05$ & $1.98 \pm 0.18$ & $1.51 \pm 0.22$ & $2.68 \pm 0.19$ & $1.48 \pm 0.08$ \\
$18: 1 \mathrm{n}-6$ & - & $0.19 \pm 0.07$ & - & $0.45 \pm 0.04$ & - \\
$\sum$ FA $^{\mathrm{b}}$ & $8.42 \pm 0.13$ & $7.65 \pm 0.77$ & $5.76 \pm 0.77$ & $10.61 \pm 0.66$ & $5.32 \pm 0.11$ \\
\hline
\end{tabular}

${ }^{\mathrm{a}} \mathrm{FA}$ : fatty acid; ${ }^{\mathrm{b}} \Sigma \mathrm{FA}$ : sum of fatty acid. Y1-Y5: yogurt samples. 
for making available the necessary technologies for the development of this research.

\section{References}

1. Sumarmono, J.; Sulistyowati, M.; J. Food Sci. 2015, 3, 2017.

2. Serafeimidou, A.; Zlatanos, S.; Kritikos, G.; Tourianis, A.; J. Food Compos. Anal. 2013, 31, 25.

3. Trigueros, L.; Sendra, E.; J. Food Sci. Technol. 2015, 60, 315.

4. Souza, S. O.; Santos, V. S.; Santos, E. S.; Ávila, D. V. L.; Nascimento, C. C.; Costa, S. S. L.; Garcia, C. A. B.; Araujo, R. G. O.; Microchem. J. 2018, 143, 2.

5. Serafeimidou, A.; Zlatanos, S.; Laskaridis, K.; Sagredos, A.; Food Chem. 2012, 134, 1839.

6. Folch, L. M.; Stanley, G. H. S.; J. Biol. Chem. 1957, 726, 497.

7. Bligh, E. G.; Dyer, W. J.; Can. J. Biochem. Physiol. 1959, 37, 911.

8. Stefanov, I.; Vlaeminck, B.; Fievez, V.; J. Food Compos. Anal. 2010, 23, 854 .

9. Liua, Z.; Rochforta, S.; Benjamin, G. C.; J. Chromatogr. A 2016, $1458,145$.

10. Figueiredo, I. L.; Claus, T.; Santos Jr., O. O.; Almeida, V. C.; Magon, T.; Visentainer, J. V.; J. Chromatogr. A 2016, 1456, 235.
11. Cruz-Hernandez, C.; Goeuriot, S.; Giuffrida, F.; Thakkar, S. K.; Destaillats, F.; J. Chromatogr. A 2013, 1284, 174.

12. Liu, Z.; Rochfort, S.; Cock, B.; Prog. Lipid Res. 2018, 741, 73.

13. Milinsk, M. C.; Matsushita, M.; Visentainer, J. V.; de Oliveira, C. C.; de Souza, N. E.; J. Braz. Chem. Soc. 2008, 19, 1475.

14. Visentainer, J. V.; Quim. Nova 2012, 35, 274.

15. International Conference on Harmonization (ICH); Validation of Analytical Procedures: Text and Methodology Q2 (R1); ICH: London, 2005.

16. International Organization for Standardization; EN ISO 5509: Animal and Vegetable Fats and Oils: Preparation of Methyl Esters of Fatty Acids; London, 1978.

17. Design Expert DX7@ software, version 7.0; Stat-Ease, Minneapolis, MN, USA, 2007.

18. Santos, L. S.; Catharino, R. R.; Aguiar, C. L.; Tsai, S. M.; Eberlin, M. N.; J. Radioanal. Nucl. Chem. 2006, 269, 505.

19. Ribani, M.; Bottoli, C. B. G.; Collins, C. H.; Jardim, I. C. S. F.; Melo, L. F. C.; Quim. Nova 2004, 27, 771.

Submitted: December 4, 2018 Published online: February 19, 2019 